\title{
Informing equitable access to cervical cancer screening in rural Sénégal: a cross-sectional study of uptake determinants
}

Jon Andrew Dykens ( $\nabla$ jdykens@uic.edu )

University of Illinois at Chicago https://orcid.org/0000-0002-4194-8725

Hamidou Thiam

Kédougou Medical Region

Caryn E. Peterson

University of Illinois at Chicago Institute for Health Research and Policy

Ellen Hendrix

University of Illinois at Chicago Institute for Health Research and Policy

Emma Luu Van Lang

Peace Corps Sénégal

Elly Lou De Jesus

University of Illinois at Chicago Institute for Health Research and Policy

Zola Collins

University of Illinois at Chicago Institute for Health Research and Policy

Tianxiu Wang

University of Illinois at Chicago Institute for Health Research and Policy

Youssoupha Ndiaye

Sénégal Ministry of Health and Social Action

Abdoul Aziz Kasse

Universite Cheikh Anta Diop

Adama Faye

Universite Cheikh Anta Diop

Jennifer S. Smith

University of North Carolina at Chapel Hill

Marian Fitzgibbon

University of Illinois at Chicago Institute for Health Research and Policy

\section{Research}

Keywords: cancer, cervical cancer, screening, uptake determinants, risk factors, health service utilization, language, knowledge, Sénégal

Posted Date: February 28th, 2020

DOI: https://doi.org/10.21203/rs.3.rs-15430/v1

License: (c) (1) This work is licensed under a Creative Commons Attribution 4.0 International License. Read Full License 


\section{Abstract}

Background: Equitable access to women's health services, including cancer prevention programs, is lacking in many countries. Sénégal ranks 17 th in the world in the age-standardized incidence rate of cervical cancer. The Kédougou region is located in the southeastern corner of Sénégal and has many structural barriers to preventive care, including economic disadvantage, a low literacy rate, and a shortage of healthcare workers. The goal of this study was to investigate the barriers and facilitators of cervical cancer screening uptake in this region.

Methods: We conducted a cross-sectional survey of 158 participants, 101 women and 57 men (ages 30 - 59) across nine non-probability-sampled communities located throughout three districts in the Kédougou region of Sénégal from October 2018 through January 2019. We collected demographic information and data on health service utilization, cervical cancer knowledge, and experience of cervical cancer screening. Associations were tested using the Fisher's Exact test statistic.

Results: The majority of our study population speaks one or both of the prevalent local languages, Malinké (62.7\%) and Pulaar (59.5\%), with fewer Wolof (26.6\%) and French (31\%) speakers. Among the women in our sample, $84.2 \%$ had never been screened for cervical cancer. Among men, $78.9 \%$ stated that they have the final say at home regarding healthcare decisions. In contrast, only $16.0 \%$ of women made their own healthcare decisions. For those who speak Malinké, $48.0 \%$ received services in another language. We found significant gender differences between women and men in the knowledge that a woman is at risk if she has multiple sexual partners $(p=0.010)$ and that a woman is at increased risk if her partner has multiple sexual partners $(p<0.001)$.

Conclusions: This study demonstrates the critical need to overcome both clinical and informational barriers, as well as structural barriers, to ensure the implementation and sustainment of an equitable health service. In this highly underdeveloped region where workforce challenges are extraordinary, innovative solutions are needed to address these underlying social determinants of health while simultaneously improving quality of care at the point of service.

Trial registration: This study is registered on clinicaltrials.gov with the Clinical Trials Study Identifier: NCT03540069

\section{Background}

Equitable access to women's health services including cancer prevention programs is lacking in many countries. Sénégal ranks 17th in the world in the agestandardized incidence rate of cervical cancer. ${ }^{1,2}$ Furthermore, while data indicating the prevalence of cervical cancer in rural regions are not available, ${ }^{3}$ human papillomavirus prevalence ${ }^{4}$ and the cervical cancer burden ${ }^{5}$ in urban areas of Sénégal is high. The estimated participation rate for cervical cancer screening in Sénégal is very low (6.9\% of all women ages 18 to 69$)$, and it is especially low in rural areas, contributing to disparity across contexts. ${ }^{4}$ As such, cervical cancer is one indicator of larger health system problems including poor access to care and the lack of culturally competent communication between provider and patient - factors that disproportionately affect poor women. ${ }^{6}$ Two of the top five World Health Organization priorities in cancer control and prevention research are to: 1) reduce access barriers to the diagnosis of curable cancers and 2) apply cancer prevention strategies in the context of local culture and resources. ${ }^{7}$ When detected at an early stage, invasive cervical cancer is one of the most successfully treated cancers. Thus, improving access to early detection will result in meaningful impact. Indeed, the five year cervical cancer survival rate ranges from $60-70 \%$ in most countries. ${ }^{8}$ Furthermore, technological innovation and efficacy testing of health service interventions including screening programs $\mathrm{s}^{9,10}$ have led to clear recommendations for improving cancer control. ${ }^{11,12}$ However, the implementation of evidence-based cervical cancer screening programs is slow and often not contextualized. Understanding barriers \& facilitators is fundamental to understanding what makes a service acceptable and sustainable.

\section{Cervical Cancer Screening Program Implementation}

In 2010, a partnership was formed between the Kédougou Medical Region in Southeastern Sénégal; the Institute of Health and Development at Cheikh Anta Diop University, Dakar, Sénégal; Peace Corps Sénégal; and the University of Illinois at Chicago. The stated overarching goal of this partnership is to achieve health equity by improving community access to quality primary healthcare services. By identifying local priorities and health service gaps, Kédougou health leaders and workers established that the aims of the partnership are to: 1) improve access to quality cervical cancer prevention services by strengthening the healthcare workforce and delivery systems in the Kédougou region and 2) inform the development and implementation of cervical cancer prevention programs in other rural regions of Sénégal.

Since 2010, the partnership has implemented and advanced a cervical cancer screening program. Partners have implemented a technical approach that is affordable and effective in low-resource settings: visual inspection of the cervix with acetic acid. ${ }^{13,14}$ In 2014 the partnership conducted a mass cervical cancer screening campaign in the Kédougou region. Community health workers provided information and education through individual and group sensitizations and radio broadcasts prior to the campaign using World Health Organization endorsed materials. ${ }^{15} \mathrm{~A}$ cross-sectional survey with regional representative sampling through a three stage cluster process with probability proportional to the number of women across 38 villages in the Kédougou region revealed that only $38 \%$ of women were aware of cervical cancer, highlighting awareness as a major barrier. The mean age was relatively young (35.7) for the total sample; only $13.8 \%$ of women were ages 40 to 44 , and $10.3 \%$ were ages 45 to 50 . Only 509 , or $5 \%$ of eligible women targeted through a mass campaign that year, were screened and only $10 \%$ were 45 years or older. ${ }^{16}$ The highest risk women, therefore, were the ones least likely to seek screening services. Despite a robust educational campaign that focused only on cervical cancer and screening service-related knowledge, screening rates through this focused effort were suboptimal. Follow-up screening rates in study sites and throughout the rest of Kédougou in the absence of a targeted campaign have continued to remain very low.

The goal of the study reported in this manuscript was to expand on our current research by investigating the determinants of cervical cancer screening uptake in this region by identifying barriers and facilitators of service uptake. These cross-sectional baseline data are being utilized in ongoing research funded by the 
National Institutes of Health to inform the adaptation of a context-specific peer education behavioral intervention through women's groups to improve screening uptake. Research supports the effectiveness of peer education and support in increasing cervical cancer screening rates ${ }^{17,18}$ but, prior to our work, no cervical cancer screening peer education program specific to the rural Sénégal context existed. These data inform our study objective to strengthen the implementation of a cervical cancer screening service in a decentralized, low-resource area of Sénégal recently naïve to any cancer screening programs by investigating the barriers and facilitators of initial uptake and developing and adapting a peer education health promotion intervention to diverse and dynamic contexts to achieve sustained utilization.

\section{Study Context}

The Kédougou region is located in the southeastern corner of Sénégal, bordering Mali and Guinea. Kédougou $(16,800$ km²) has an estimated population of 178,269 in 2018 , representing about $1 \%$ of the population of Sénégal. ${ }^{19}$ The region is economically disadvantaged, with $61.3 \%$ of households categorized at the most impoverished level in Sénégal, and only $1.3 \%$ of the households on par with the richest households in Sénégal. In this region, women are much more likely to be unemployed than men ( $46.4 \%$ and $8.3 \%$ respectively). Moreover, the French literacy rate in this region was estimated to be $30.2 \%$ in 2013 , with lower levels in rural areas. The school attendance rate is $44 \%{ }^{20}$ and there is a shortage of healthcare workers. In 2018 , there were 11 physicians (including a single gynecologist), 48 midwives, 32 registered nurses, 6 technicians, and 1 social worker providing care for the entire region. ${ }^{20,21}$ Therefore, there are considerable challenges to achieving health equity in this region as compared to other more developed areas of Sénégal.

\section{Methods}

We conducted a cross-sectional survey of 158 participants, 101 women and 57 men (ages 30-59) across nine non-probability-sampled communities (two rural and one semi-urban from each district, across three districts) in the Kédougou region of Sénégal from October 2018 through January 2019 . We collected demographic information and data on health service utilization, cervical cancer knowledge, and experience of cervical cancer screening through intervieweradministered surveys. The surveys were administered to one woman and one man per 10 randomly selected households and five women per women's group within each community. Survey interviews were conducted in the participants' choice of language: French, Malinké, or Pulaar. Participants were eligible for inclusion in the study if they were between 30-59 years old and were female, or were a male living with a female who was able to seek cervical cancer prevention services from a health facility in the Kédougou region of Sénégal. Individuals who were outside the target age-range were not eligible for participation.

\section{Site Selection and Recruitment}

The region of Kédougou is divided into three medical districts: Kédougou, Saraya, and Salémata. Each of these health districts has a single health center in the district capital and multiple health posts in the surrounding rural communities. We selected nine sites in the Kédougou Medical Region through non-probability sampling, including one health center and two rural health posts from each of the three districts comprising the region. In the Kédougou District, we selected the Dalaba health post (population accessing this health post =5995), Bandafassi (7189), and Dindefello (9370). In the Salémata District, we selected the Salémata Health Center (7278) and the health posts of Dar Salaam (3084) and Dakately (3037). In the Saraya District, we selected the Saraya Health Center (5890) and the posts of Nafadji (3759) and Khossanto (3471). Each of the nine sites was mapped through OpenStreetMaps. ${ }^{22}$ Printable maps were created (using FieldPapers ${ }^{23}$ ) to illustrate structures (assumed to be households), roads, and rivers in each site. Maps were divided into four sectors with approximately the same number of structures in each quadrant. Structures were numbered and Google's random number generator was used to determine the starting point. Counting in increments of the limiting factor, each chosen structure was marked and recorded. This ensured a relatively even distribution of structures selected throughout each site. Twenty structures per site $(n=180)$ were selected and visited in order to assess for eligibility. Potential participants were recruited using the approved recruitment script. Households were selected if there were both an eligible woman and man who agreed to participate. An additional five women per site were recruited from existing women's groups in order to strengthen the assessment at the community level.

\section{Development of Documents}

The questionnaire included closed-ended, quantitative questions seeking information regarding demographics, health service utilization, cervical cancer risk factors, cervical cancer knowledge, and indicators related to cervical cancer screening experience. The questionnaires were first created in English, translated into French and the local languages of Jahanké/Malinké and Pula Fuuta (a dialect of Fula/Pulaar), and then back-translated for accuracy by certified Sénégalese translators. Questionnaires were field tested for comprehension prior to the initiation of the study. All IRB-approved documents including study overview, recruitment scripts, and the informed consent were available in French, Malinké, and Pulaar.

\section{Consent and Data Collection}

All research assistant data collectors participated in a three-day training on the project protocol, including data collection methodology facilitated by the lead investigator prior to field testing the instrument. After final institutional review board approval, research assistants attended an additional three-day training to review all data collection procedures. The study research assistants read the informed consent aloud, in the participants' preferred language, and participants reviewed and signed the approved informed consent short form, written in French. In cases where the participant did not read French, a trusted contact was requested by the participant to witness the informed consent process, observe the signature of the participant, and then sign as a witness. After participants were consented, data collection was conducted immediately with a female research assistant collecting data from women and a male research assistant collecting data from men. All data collection activities were performed in a private setting. Data collection interviews occurred in the preferred language of the participant. All responses were recorded on hard copy interview forms with the name of the participant being the only item recorded on the final page. All data collection instruments were immediately handed over to the lead research assistant, who recorded the participant's name on the participant code book, placed 
a unique identifier on page one of the data collection instrument, removed and destroyed the final page of each instrument, scanned all documents, and transmitted them through a secure portal to a research assistant in the United States.

\section{Data Analysis}

Data were double-entered into an electronic spreadsheet by two research assistants, compared, approved and subsequently cleaned by the principal investigator. Bivariate analyses were conducted to assess 1) behavioral and clinical risk factors associated with cervical cancer screening in our population, 2) gender differences in health service barriers and utilization as well as cervical cancer knowledge, 3) language provision by preferred language for Malinké speakers, and 4) differences in the experience of being screened for cervical cancer within our sample. Associations were tested using the Fisher's Exact test statistic (by way of the Two- Stage Fisher's Exact Test using RStudio version 1.2.1578 through the Dplyr and Arsenal packages).

\section{The Conduct of Responsible Research and Partnership}

The University of Illinois at Chicago has an ongoing partnership affiliation agreement with the Institute of Health and Development at the University Cheikh Anta Diop and with the Medical Region of Kédougou. This partnership uses a participatory approach ensuring that all activities are well-aligned with the expressed priorities of the local health system. This study was approved through the University of Illinois at Chicago and Sénégal University Cheikh Anta Diop research ethics committees. The Medical Region of Kédougou, the three health districts, and participating health posts granted researchers permission through signed letters of support to implement and conduct the data collection activities. Each investigator and U.S. based research assistant received the Collaborative Institutional Training Initiative training certification prior to conducting the research. ${ }^{24}$ All local research assistants were trained in research ethics through a locally approved ethics of human research training program.

\section{Results}

We surveyed 101 women and 57 men between December 2018 and February 2019. The mean age of participants was 41.6 years with the mean age of men (44.1 years) being slightly higher than the mean age of women ( 40.2 years, $p=0.006)$. There were significant gender differences in educational level ( $p$ $<0.001$ ). Among those surveyed, $97 \%$ of all women and $76.8 \%$ of all men had no more than a primary education, while $25.7 \%$ of women and $10.3 \%$ of men had no education at all. No women in our sample attended more than two years of secondary school, while $8.9 \%$ of men were educated beyond two years of secondary school, and an additional $7.1 \%$ had at least some university education. The majority of participants ( $92.1 \%$ of women and $94.7 \%$ of men) were married, and among all women, $51.5 \%$ were in a polygamous household as related to significant gender differences in marital status $(p=0.004)$. The majority of our study population spoke one or both prevalent local languages, Malinké (62.7\%) and Pulaar (59.5\%). As is characteristic for the region, there are fewer Wolof (26.6\%) and French (31\%) speakers in our sample. It should be noted that there are significantly more male Wolof (36.8\%) than female Wolof (20.8\%) speakers $(p=0.039)$ as well as male French $(45.6 \%)$ than female French $(22.8 \%)$ speakers $(p=0.004)$. Among the women in our sample, $84.2 \%$ have never been screened for cervical cancer, $13.9 \%$ have been screened one time, and $2.0 \%$ have been screened multiple times (Table 1 ).

The mean age of women who were screened in our study is 42.4 years, with a range of 32 to 54 years. The mean age of the reported initiation of sexual activity among our study population overall was 16.7 years old, and the mean age of first pregnancy was 17.8 years. The mean number of lifetime births among women was 4.6. None of the women in our study sample were current smokers, $22.8 \%$ had a history of sexually transmitted infections, and $67.3 \%$ had no history of using oral contraceptives. We found significant differences by screening status in two categories. Women who were screened had a higher number of lifetime births $(p=0.016)$ and were more likely to report a history of a sexually transmitted infection $(S T I)(p=0.047)($ Table 2$)$.

We found significant gender differences for certain health service utilization barriers and facilitators, including adequate support for duties when not able to work $(p=0.003)$, healthcare provider gender $(p<0.001)$, comfort with healthcare provider $(p=0.007)$, avoidance of healthcare due to cost $(p=0.044)$, use of personal funds to pay for healthcare $(p<0.001)$, spouse assistance with healthcare costs $(p<0.001)$, personal final say at home for healthcare decisions $(p<$ $0.001)$, and spousal healthcare decision power $(\mathrm{p}<0.001)$. A large portion of the study population $(92.6 \%)$ stated that they have enough time to take care of their healthcare needs. The large majority of both women (88.7\%) and men (100\%) feel comfortable with their healthcare provider. Both women (35.0\%) and men $(51.8 \%)$ stated that at some point they have avoided going to the health facility because they could not afford the cost. Over half (52.0\%) of the women use their own limited funds, while $30.0 \%$ are dependent on their spouse to pay for the healthcare. Among men, $78.9 \%$ stated that they have the final say at home regarding healthcare decisions. In contrast, only $16.0 \%$ of women reported making their own healthcare decisions, with $72 \%$ stating that their spouse made all the healthcare decisions. Of note, while there is not a significant gender difference, $18.8 \%$ of all participants stated that they had a negative experience at the health facility at some point when receiving care in Sénégal (Table 3).

When analyzing the language used in the healthcare setting with Malinké speakers, we identified several significant findings. There are differences between Malinké speakers and non-Malinké speakers in whether health services have been conducted in Malinké $(p<0.001)$, Wolof $(p=0.006)$, or French $(p<0.001)$. For those that speak Malinké, $48.0 \%$ received services in another language. Only $52.0 \%$ of Malinké speakers in our sample stated that they sometimes receive care in Malinké, $44.9 \%$ have received care at some point in Wolof, and $54.1 \%$ have at some point received care in French. Among participants, $34.4 \%$ did not receive any language interpretive services (formal or informal) (Table 4).

Concerning knowledge about cervical cancer, we found significant gender differences between women and men in the knowledge that a woman is at risk if she has multiple sexual partners $(p=0.010)$, a woman is at increased risk if her partner has multiple sexual partners $(p<0.001)$, smoking increases the risk of cervical cancer $(p=0.008)$, intrauterine devices (IUDs) offer a protective benefit against cervical cancer, $(p=0.006)$, oral contraceptive pills increase the risk of cervical cancer $(p=0.012)$, and that screening continues to be recommended for women after menopause $(p<0.001)$. About one third $(31.6 \%)$ of the study population was unaware of cervical cancer at the time of this survey, equally split among the genders (31.7\% of women and $31.6 \%$ of men). Likewise, only $52.2 \%$ of our study population was aware of the cervical cancer screening test. However, $94.8 \%$ of all respondents correctly stated $(27.7 \%$ Agree and $67.1 \%$ Strongly Agree) that it is important for a woman to get screened for cervical cancer even if she has no symptoms. In addition, $87.8 \%$ of women either agreed 
(33.7\%) or strongly agreed (54.1\%) that a woman is more likely to get cervical cancer if she has had multiple sexual partners, whereas $67.9 \%$ of men either agreed $(28.6 \%)$ or strongly agreed $(39.3 \%)$ that a woman is more likely to get cervical cancer if she has had multiple sexual partners. When asked about the sexual behavior of men, $90.9 \%$ of women either agreed (28.3\%) or strongly agreed (62.6\%) that a woman is more likely to get cervical cancer if her husband has had multiple sexual partners, while only $37.5 \%$ of men either strongly agreed to this statement. Among women, $30.3 \%$ were undecided, $10.1 \%$ disagreed, and $9.1 \%$ strongly disagreed that a woman is less likely to get cervical cancer if she uses an IUD. Concerning the oral contraceptive pill, $24.5 \%$ of women were undecided, $13.3 \%$ disagreed, and $9.2 \%$ strongly disagreed that it increases the risk of cervical cancer. A large number of women are unaware that cervical cancer screening is recommended after menopause ( $8.1 \%$ are undecided, $44.4 \%$ disagree, and $12.1 \%$ strongly disagree). Men, as well, are largely unaware of this recommendation, with $32.7 \%$ being undecided, $18.2 \%$ disagree, and $25.5 \%$ strongly disagree. Among all respondents, a considerable number agreed (37.8\%) or strongly agreed (51.9\%) that If cervical cancer is found early, it can be cured (Table 5 ).

Among the women in our sample, $84.2 \%$ of women had never been screened for cervical cancer, with $14 \%$ having been screened a single time, while $2 \%$ have had multiple screenings. Only three women have been screened within the last 2 years. Among all women who have been screened, $75 \%$ strongly agree that they are satisfied with the screening and $50.0 \%$ strongly agree that the test was comfortable. In addition, $66.7 \%$ strongly agree that there was a lengthy wait time for screening, while $83.3 \%$ strongly agree that they received adequate orientation to the screening exam (Table 6).

\section{Discussion}

The principal objective of this study was to investigate the determinants of cervical cancer screening uptake in the Kedougou region of Sénégal to inform the adaptation of a context-specific peer education behavioral intervention through women's groups to improve screening uptake. We have identified several notable knowledge gaps that are being addressed through the developed educational curriculum. We will measure the impact of the educational program on uptake of the screening service post-intervention. However, current data analysis suggests the importance of social determinants (gender, socioeconomic status, and language of communication), as well as quality of care at the primary healthcare level, as factors requiring additional research.

\section{Risk Factors and Knowledge}

Among the cervical cancer behavioral and clinical risk factors that we measured (Table 2), we found a significant difference between non-screened and screened women in the number of lifetime births and history of sexually transmitted infections. There are some knowledge gaps regarding cervical cancer among both genders in our sample. However, it is interesting to note that there is widespread agreement concerning the importance of screening for prevention, before the development of signs or symptoms of cancer. Women are more knowledgeable about the risks associated with multiple sexual partners, including the risk associated with their spouse having more sexual partners. Both women and men need a stronger understanding of cervical cancer risk among older women, indicated by the measure stating that screening is recommended after menopause, with women being somewhat more aware of the risk with advancing age. Given that a prior study in this region indicated that older women are less likely to seek cervical cancer screening, this is a notable knowledge gap. ${ }^{16}$ Increased cervical cancer education is needed, including strategies and messages targeted to each gender.

\section{Healthcare utilization}

A considerable number of health service utilization barriers are a reality in this very rural area. In a region that is economically disadvantaged, where educational opportunities are very limited, especially for women, and where men are the principal decision-makers concerning healthcare utilization, there are numerous barriers for a woman to seek needed healthcare. While costs are relatively minimal (around US\$ 1 per consultation), the actual or perceived financial burden may contribute to the avoidance of healthcare due to cost, as evidenced by our data. The perceived costs of cervical cancer screening may be an additional burden that this study has not fully explored. Anecdotally, people in this region have expressed concern about potential travel and treatment expenses that may be associated with a cancer diagnosis. This perceived cost burden is especially problematic for women, given that some women have little to no control over household finances. Over $50 \%$ of the women in our sample need to use their own limited personal funds, given their being largely financially dependent on their husbands. Furthermore, while women $(55.0 \%)$ are more likely than men $(29.8 \%)$ to state that they have adequate support from others to assist with their daily work and responsibilities, this still leaves $45.0 \%$ of women with minimal opportunity to free themselves to seek needed care.

\section{Language}

Because Kedougou is a highly disadvantaged region with a very low educational level, Sénégal is not able to train enough healthcare professionals originating from this region in order to fill the required positions. Therefore, clinicians from the economic centers (who tend to be Wolof and French speakers) are posted to Kedougou (where the principal spoken languages are Malinké and Pulaar) through the public health service for a three to five year stint. Given that Kedougou is a hardship region with a poor educational system and few economic opportunities, many of these professionals move here without their families. They are posted to the region without any prior language or cultural training and, given the social challenges, often leave the region before they have been able to develop adequate language skills. However, In this rural region, local languages are the preferred language of communication. The large majority of our study population speaks either Malinké or Pulaar, with relatively few Wolof and French speakers. As such, the language in which clinical care is conducted is a critical indicator to the quality of care in the region and, unfortunately, is a significant barrier to receiving high quality care for many in this region. This barrier likely impedes the ability of the clinicians to educate patients on health services that may be available, including cervical cancer prevention services. In addition, as shown by our data, women are especially disempowered to seek the information and care that they may desire.

\section{Quality}

Even though most women who received the screening test were satisfied with the exam, the experiential indicators suggest that there is room for improvement in the quality of the service that is being provided. Of the women screened, $16.7 \%$ strongly disagreed that the test was comfortable. Our data do not suggest a 
correlation between comfort and recommendation, however, we should be cautious in this conclusion given the low numbers of women screened within the study population. Most women did report having been adequately oriented to the exam, but we are wary of interpreting this as an indicator of high quality given the concerning data regarding translation at the point of care as described above. Concerns for quality of care are reinforced by evidence that $16.3 \%$ of women and $23.2 \%$ of men stated that they had been treated badly at some point when receiving care in Sénégal. Quality of care challenges are likely to discourage utilization of the health service.

\section{Limitations}

There were some limitations in the methodology used to recruit households within each site. Every structure on the map was assumed to be a household and was thus included in the count, as specific household information was not provided. In reality, this was not the case - some structures were businesses, vacant, or not present. When encountering this scenario, we progressed to the next marked structure on the list. In addition, the satellite images used to create the maps on OpenStreetMaps may have been outdated. For example, Khossanto has rapidly expanded within a short amount of time due to gold mining. Thus, newer structures were not shown on the map we had and were, therefore, not included in the count. For a few of the villages (Kedougou and Bandafassi in particular), there are nearby sites that may be considered either a separate village that falls within the health posts' treatment area or an actual part of the health post village, depending on who is asked. These communities are assumed to seek care at the health posts in the communities we surveyed, but they were not included in our methodology because 1) they have yet to be mapped and 2) it is unclear on whether they are a neighborhood or a village. In some cases, data collection was attempted separately from the recruitment and consent process. This may have resulted in the inability to collect data from some of the selected households due to the participant being away during the day(s) that the research assistant was present. Finally, we must use caution in interpreting these results, given the low numbers of women within our study sample who have been screened for cervical cancer. We will follow the trend of these indicators over time as women are exposed to the peer education program.

\section{Conclusions}

In a region where women are not educated, not literate, have no or little monetary resources and cannot make their own health care decisions it is very difficult to have them participate in their own preventive health care. These are major impediments that cannot be solved in the short-term, however, our goal is to identify the means of empowering women to reduce their risk of cancer within this context. Our study shows that in order to implement and sustain an equitable cervical cancer screening health service in this rural region, there are several quality indicators that need to be addressed. There are multiple barriers, including perceptions of cost, that will need to be confronted to ensure health service utilization. Women's inability to make their own healthcare decisions and to leave their work at home in order to seek healthcare are included among the barriers that need to be addressed. It is important, as well, to ensure that sensitization efforts target men to encourage shared decision making. This study also highlights the need to research and address the indication that many individuals have had negative experiences within the health system. The language barrier is considerable, and necessitates not only ensuring that providers speak the local language, but that educational materials and informational sessions are provided in the language of choice of the recipient. These efforts may begin to stem the challenges of ensuring high quality communication at the point of care and within the community. In addition, we will need to ensure that clinicians are well trained in the manner of providing comfortable care to address the identified barrier of an uncomfortable speculum exam.

This study has indicated that there are not only clinical and informational barriers that we will need to overcome to ensure the implementation and sustainment of an equitable health service, but structural barriers as well. In this region that is highly underdeveloped and where workforce challenges are extraordinary, innovative solutions are needed to address underlying social determinants of health while at the same time improving quality of care at the point of service.

\section{Declarations}

\section{Ethics approval and consent to participate}

This study was approved through the University of Illinois at Chicago (UIC2016-0947) and Sénégal University Cheikh Anta Diop (SEN17/75) research ethics committees. Written informed consent was acquired from each participant prior to initiation of data collection.

\section{Consent for publication}

Not applicable

\section{Availability of data and materials}

All data generated or analysed during this study are included in this published article [and its supplementary information files].

\section{Competing interests}

The authors declare that they have no competing interests

\section{Funding}


Research reported in this publication was supported by the Fogarty International Center of the National Institutes of Health under Award Number K01TW010494. The content is solely the responsibility of the authors and does not necessarily represent the official views of the National Institutes of Health. This research was also supported in part by the Department of Family Medicine and the Center for Global Health at the University of Illinois at Chicago.

\section{Authors' contributions}

All authors contributed to the conception and design of the study (JAD, HT, CEP, ZC, YN, AAK, JSS, MF) or to the acquisition, analysis and interpretation of data (EH, ELVL, ELDJ, TW, AF, ), and drafted the manuscript (JAD, CEP, TW) or revised it critically for content (HT, EH, ELVL, ELDJ, ZC, YN, AAK, AF, JSS, MF). All authors read and approved the final manuscript.

\section{Acknowledgements}

The authors would like to acknowledge and thank all officials at the Kedougou regional level including Cheikh Senghor MD and Dr. David Ngom MD. We are also grateful to other health system personnel at the Kedougou district: Fatoumata Traore, Moussa Ndiaye MD, Marguerite Thiare, Bakary Boubou Traore, the Saraya District: Evrard Kabou MD, Daouda Gueye, and the Salémata District: Mamadou Moustapha Thioub. We are also extraordinarily indebted to the local research assistants who ensured that all of the work was accomplished. These amazing individuals include Hawa Diallo, Fatoumata Dia, Dib Faye, Tahibou Niang, Lamine Doucare, Moussa Salife Sidibe, Bintou Samoura, and Moussoucouta Samoura. We are also very grateful to the Peace Corps administrators and volunteers who have supported this project. These extraordinary individuals include Cheryl Faye, Mamadou Diaw, Maureen Cunningham, Adji Thiaw, Imane Sene, Pape Camara, Carmen Dibaya, Maria Castrillon, Ethan Quinn, Brendan Gray, Elizabeth Costello, Emma Murphy, Cason Kirby, and Regina Siedow. In addition, we are grateful for those who have provided support from the University of Illinois at Chicago for this project. Many thanks to John Hickner MD, Memoona Hasnain MD MHPE PhD, Stevan Weine MD, Marc Atkins PhD, Michael Berbaum PhD as well as those who have supported the grant management at the Institute of Health Policy and Research including Julieth Pineros, Erika Magallenos, Rocio Bueno, and Przemyslaw Racinski among many others. We are also grateful to David Peters MD DrPH for mentorship in the early development of this project.

\section{References}

1. Demment MM, Peters K, Dykens JA, Dozier A, Nawaz H, Mclntosh S, et al. Developing the Evidence Base to Inform Best Practice: A Scoping Study of Breast and Cervical Cancer Reviews in Low- and Middle-Income Countries. PLoS One [Internet]. 2015 Sep 1;10(9):e0134618. Available from: http://dx.doi.org/10.1371/journal.pone.0134618

2. Ferlay J, Ervik M, Lam F, Colombet M, Mery L, Piñeros M, et al. Global Cancer Observatory: Cancer Today [Internet]. Lyon, France: International Agency for Research on Cancer. 2018 [cited 2019 Sep 11]. Available from: https://gco.iarc.fr/today/home

3. Woto-Gaye G, Critchlow C, Kiviat N, Ndiaye PD. Cytological detection of cervical cancer in black Africa: what are the perspectives? Bulletin of Cancer. 1996;83(5 SRC - GoogleScholar):407-9.

4. Bruni L, Albero G, Serrano B, Mena M, Gómez D, Muñoz J, et al. Human Papillomavirus and Related Diseases in Senegal. Summary Report [Internet]. ICO/IARC Information Centre on HPV and Cancer (HPV Information Centre); 2018. Available from: http://www.hpvcentre.net/statistics/reports/SEN.pdf

5. Xi LF, Touré P, Critchlow CW, Hawes SE, Dembele B, Sow PS, et al. Prevalence of specific types of human papillomavirus and cervical squamous intraepithelial lesions in consecutive, previously unscreened, West-African women over 35 years of age. Int J Cancer [Internet]. 2003 Mar 1;103(6):803-9. Available from: http://dx.doi.org/10.1002/ijc.10876

6. Freeman HP, Chu KC. Determinants of cancer disparities: barriers to cancer screening, diagnosis, and treatment. Surg Oncol Clin N Am [Internet]. 2005 Oct;14(655-9):655-69, v. Available from: http://dx.doi.org/10.1016/j.soc.2005.06.002

7. A prioritized research agenda for prevention and control of noncommunicable diseases. World Health Organization http://www.who.int/cardiovascular_diseases/publications/ncd_agenda2011/en/; 2011.

8. Allemani C, Weir HK, Carreira H, Harewood R, Spika D, Wang X-S, et al. Global surveillance of cancer survival 1995-2009: analysis of individual data for 25,676,887 patients from 279 population-based registries in 67 countries (CONCORD-2). Lancet [Internet]. 2015 Mar 14;385(9972):977-1010. Available from: http://dx.doi.org/10.1016/S0140-6736(14)62038-9

9. Beasley JW, Starfield B, van Weel C, Rosser WW, Haq CL. Global health and primary care research. J Am Board Fam Med [Internet]. 2007 Nov;20(51826):518-26. Available from: http://dx.doi.org/10.3122/jabfm.2007.06.070172

10. Gonzalez-Block MA. Health policy and systems research agendas in developing countries. Health Res Policy Syst [Internet]. 2004 Aug 5;10(1186/1478):6. Available from: http://www.ncbi.nlm.nih.gov/sites/entrez?

$\mathrm{Db}=$ pubmed\&DbFrom=pubmed\&Cmd=Link\&LinkName=pubmed_pubmed\&LinkReadableName=Related\%20Articles\&ldsFromResult=15296509\&ordinalpo:

11. Cancer Control: Knowledge Into Action : WHO Guide for Effective Programmes [Internet]. World Health Organization; 2007. 42 p. Available from: http://books.google.com/books/about/Cancer_Control.html?hl=\&id=GL8IAQAAMAAJ

12. Brown ML, Goldie SJ, Draisma G, Harford J, Lipscomb J. Health Service Interventions for Cancer Control in Developing Countries. In: Jamison DT, Breman JG, Measham AR, Alleyne G, Claeson M, Evans DB, et al., editors. Disease Control Priorities in Developing Countries [Internet]. Washington (DC): World Bank; 2011. Available from: https://www.ncbi.nlm.nih.gov/pubmed/21250334

13. Sauvaget C, Fayette J-M, Muwonge R, Wesley R, Sankaranarayanan R. Accuracy of visual inspection with acetic acid for cervical cancer screening. Int $J$ Gynaecol Obstet [Internet]. 2011 Apr;113(14-24):14-24. Available from: http://dx.doi.org/10.1016/j.ijgo.2010.10.012 
14. Goldie SJ, Kuhn L, Denny L, Pollack A, Wright TC. Policy analysis of cervical cancer screening strategies in low-resource settings: clinical benefits and cost-effectiveness. JAMA [Internet]. 2001 Jun 27;285(3107-15):3107-15. Available from: http://www.ncbi.nlm.nih.gov/sites/entrez?

$\mathrm{Db}=$ pubmed\&DbFrom=pubmed\&Cmd=Link\&LinkName=pubmed_pubmed\&LinkReadableName=Related\%20Articles\&IdsFromResult=11427139\&ordinalpo:

15. World Health Organization. Comprehensive Cervical Cancer Control: A Guide to Essential Practice [Internet]. 2nd edition. Geneva: World Health Organization; 2014. 404 p. (Integrating Heath Care for Sexual and Reproductive Health and Chronic Diseases). Available from:

https://market.android.com/details?id=book-4uZlrgEACAAJ

16. Dykens JA, Linn AM, Irwin T, Peters KE, Pyra M, Traoré F, et al. Implementing visual cervical cancer screening in Senegal: a cross-sectional study of risk factors and prevalence highlighting service utilization barriers. Int J Womens Health [Internet]. 2017 Jan 27;9:59-67. Available from:

http://dx.doi.org/10.2147/IJWH.S115454

17. Agide FD, Garmaroudi G, Sadeghi R, Shakibazadeh E, Yaseri M, Koricha ZB, et al. A systematic review of the effectiveness of health education interventions to increase cervical cancer screening uptake. Eur J Public Health [Internet]. 2018 Dec 1;28(6):1156-62. Available from:

http://dx.doi.org/10.1093/eurpub/cky197

18. Sadoh AE, Okonkwobo C, Nwaneri DU, Ogboghodo BC, Eregiea C, Oviawe O, et al. Effect of Peer Education on Knowledge of Human Papilloma Virus and Cervical Cancer among Female Adolescent Students in Benin City, Nigeria. Ann Glob Health [Internet]. 2018 Apr 30;84(1):121-8. Available from:

http://dx.doi.org/10.29024/aogh.24

19. Beye AS, Ndir B, Dieng M, Thioune A, Magassouba N, Cissoko FA. Regional Economic and Social Situation of Kedougou in 2014 [Internet]. Kédougou Regional Service of Statistics and Deomgraphics, National Statistics and Demographics Agency of Senegal; 2014. Available from: http://www.ansd.sn/ressources/ses/SES-Kedougou-2014.pdf

20. Ndir B, Sene PIS, Ndiaye S, Diouf M. The Population of Senegal in 2017 [Internet]. National Statistics and Demographics Agency, Demographic and Social Statistics Division; 2017. Available from: http://www.ansd.sn/ressources/publications/Rapport_population_2017_05042018.pdf

21. Sénégal: Continuous Survey on the Provision of Health Care Services (ECPSS) [Internet]. Rockville, Maryland, USA: Agence Nationale de la Statistique et de la Démographie (ANSD) [Sénégal] and ICF; 2017. Available from: http://www.ansd.sn/ressources/rapports/Rapport\%20Final\%20ECPSS\%202017.pdf

22. OpenStreetMap [Internet]. OpenStreetMap. [cited 2019 Nov 21]. Available from: https://www.openstreetmap.org/\#map=7/14.510/-14.446

23. Field Papers [Internet]. [cited 2019 Nov 21]. Available from: http://fieldpapers.org/

24. Braunschweiger P, Goodman KW. The CITI program: an international online resource for education in human subjects protection and the responsible conduct of research. Acad Med [Internet]. 2007 Sep;82(9):861-4. Available from: http://dx.doi.org/10.1097/ACM.0b013e31812f7770

\section{Tables}

Table 1: Demographics by gender 


\begin{tabular}{|c|c|c|c|c|}
\hline Age in years & & & & 0.006 \\
\hline Mean (SD) & $40.168(8.631)$ & $44.140(8.355)$ & 41.601 (8.718) & \\
\hline Range & $30.000-59.000$ & $30.000-59.000$ & $30.000-59.000$ & \\
\hline Education level & & & & $<0.001$ \\
\hline None & $26(25.7 \%)$ & $5(8.9 \%)$ & $31(19.7 \%)$ & \\
\hline Quranic School & $35(34.7 \%)$ & $21(37.5 \%)$ & $56(35.7 \%)$ & \\
\hline Primary education & $37(36.6 \%)$ & $17(30.4 \%)$ & $54(34.4 \%)$ & \\
\hline Secondary school through university & $3(3.0 \%)$ & $13(23.2 \%)$ & $16(10.2 \%)$ & \\
\hline Marital status & & & & 0.073 \\
\hline Single, divorced, separated, or widowed & $8(7.9 \%)$ & $3(5.3 \%)$ & $11(7.0 \%)$ & \\
\hline Married (monogamous household) & $41(40.6 \%)$ & $34(59.6 \%)$ & $75(47.5 \%)$ & \\
\hline Married (polygamous household) & $52(51.5 \%)$ & $20(35.1 \%)$ & $72(45.6 \%)$ & \\
\hline Malinké speaker & & & & 0.733 \\
\hline No & $39(38.6 \%)$ & $20(35.1 \%)$ & $59(37.3 \%)$ & \\
\hline Yes & $62(61.4 \%)$ & $37(64.9 \%)$ & $99(62.7 \%)$ & \\
\hline Pulaar speaker & & & & 0.019 \\
\hline No & $48(47.5 \%)$ & $16(28.1 \%)$ & $64(40.5 \%)$ & \\
\hline Yes & $53(52.5 \%)$ & $41(71.9 \%)$ & $94(59.5 \%)$ & \\
\hline Wolof speaker & & & & 0.039 \\
\hline No & $80(79.2 \%)$ & $36(63.2 \%)$ & $116(73.4 \%)$ & \\
\hline Yes & $21(20.8 \%)$ & $21(36.8 \%)$ & $42(26.6 \%)$ & \\
\hline French speaker & & & & 0.004 \\
\hline No & $78(77.2 \%)$ & $31(54.4 \%)$ & 109 (69.0\%) & \\
\hline Yes & $23(22.8 \%)$ & $26(45.6 \%)$ & 49 (31.0\%) & \\
\hline \multicolumn{5}{|l|}{ Screened for cervical cancer } \\
\hline Never screened & $85(84.2 \%)$ & 0 & $85(84.2 \%)$ & \\
\hline One time only & $14(13.9 \%)$ & 0 & $14(13.9 \%)$ & \\
\hline More than one time & $2(2.0 \%)$ & 0 & $2(2.0 \%)$ & \\
\hline
\end{tabular}


Table 2: Behavioral and Clinical Risk Factors associated with cervical cancer screening in our population

\begin{tabular}{|c|c|c|c|c|}
\hline & $\begin{array}{l}\text { Never screened } \\
\qquad(\mathrm{N}=85)\end{array}$ & $\begin{array}{l}\text { Screened } \\
(\mathrm{N}=16)\end{array}$ & $\begin{array}{c}\text { Total } \\
(\mathrm{N}=101)\end{array}$ & $\mathrm{p}$ value \\
\hline SDz_Age & & & & 0.254 \\
\hline Mean (SD) & $39.7(9.020)$ & $42.4(5.876)$ & $40.2(8.631)$ & \\
\hline Range & $30.0-59.0$ & $32.0-54.0$ & $30.0-59.0$ & \\
\hline Age of initiation of sexual activity & & & & 0.708 \\
\hline Mean (SD) & $16.716(2.273)$ & $16.462(2.145)$ & $16.678(2.244)$ & \\
\hline Range & $11.000-25.000$ & $13.000-22.000$ & $11.000-25.000$ & \\
\hline Age of first pregnancy & & & & 0.114 \\
\hline Mean (SD) & $17.645(2.711)$ & $18.812(2.373)$ & $17.848(2.681)$ & \\
\hline Range & $11.000-26.000$ & $15.000-23.000$ & $11.000-26.000$ & \\
\hline Number of lifetime births & & & & 0.016 \\
\hline Mean (SD) & $4.398(2.072)$ & $5.750(1.653)$ & $4.616(2.064)$ & \\
\hline Range & $0.000-10.000$ & $3.000-8.000$ & $0.000-10.000$ & \\
\hline Smoking history & & & & 0.158 \\
\hline I have smoked in the past-but I no longer smoke & $0(0.0 \%)$ & $1(6.2 \%)$ & $1(1.0 \%)$ & \\
\hline No-l have never smoked & $85(100.0 \%)$ & $15(93.8 \%)$ & $100(99.0 \%)$ & \\
\hline Sexually transmitted infection history & & & & 0.047 \\
\hline No & $69(81.2 \%)$ & $9(56.2 \%)$ & $78(77.2 \%)$ & \\
\hline Yes & $16(18.8 \%)$ & $7(43.8 \%)$ & $23(22.8 \%)$ & \\
\hline Oral contraceptive use history & & & & 0.146 \\
\hline No & $60(70.6 \%)$ & $8(50.0 \%)$ & $68(67.3 \%)$ & \\
\hline Yes & $25(29.4 \%)$ & $8(50.0 \%)$ & $33(32.7 \%)$ & \\
\hline
\end{tabular}

Table 3: Health service utilization determinants by gender 
I have time to take care of my health

No

Yes

I have help to maintain my duties when I cannot work

No

Yes

Healthcare provider gender

Female

Male

I am comfortable with my healthcare provider

No

Yes

I have avoided seeking healthcare due to cost

No

Yes

I use personal funds to pay for my healthcare

No

Yes

My spouse provides funds for my healthcare expenses

No

Yes

I have the final say at home regarding my healthcare decisions

No

Yes

My spouse has the final say at home regarding my healthcare decisions

No

Yes

I have been treated badly in past at a Sénégal health facility
0.105

$\begin{array}{ccc}4(4.3 \%) & 7(12.3 \%) & 11(7.4 \%) \\ 88(95.7 \%) & 50(87.7 \%) & 138(92.6 \%)\end{array}$

0.003

$\begin{array}{lll}45(45.0 \%) & 40(70.2 \%) & 85(54.1 \%) \\ 55(55.0 \%) & 17(29.8 \%) & 72(45.9 \%)\end{array}$

$<0.001$

$\begin{array}{lrr}23(26.1 \%) & 0(0.0 \%) & 23(16.1 \%) \\ 65(73.9 \%) & 55(100.0 \%) & 120(83.9 \%)\end{array}$

0.007

$11(11.3 \%)$

$0(0.0 \%)$

$11(7.2 \%)$

$86(88.7 \%) \quad 56(100.0 \%) \quad 142(92.8 \%)$

0.044

$65(65.0 \%) \quad 27(48.2 \%) \quad 92(59.0 \%)$

$35(35.0 \%) \quad 29(51.8 \%) \quad 64(41.0 \%)$

$<0.001$

$48(48.0 \%) \quad 4(7.0 \%) \quad 52(33.1 \%)$

$52(52.0 \%) \quad 53(93.0 \%) \quad 105(66.9 \%)$

$<0.001$

$70(70.0 \%) \quad 57(100.0 \%) \quad 127(80.9 \%)$

$30(30.0 \%) \quad 0(0.0 \%) \quad 30(19.1 \%)$

$<0.001$

$84(84.0 \%) \quad 12(21.1 \%) \quad 96(61.1 \%)$

$16(16.0 \%) \quad 45(78.9 \%) \quad 61(38.9 \%)$

$<0.001$

$\begin{array}{lll}28(28.0 \%) & 52(91.2 \%) & 80(51.0 \%) \\ 72(72.0 \%) & 5(8.8 \%) & 77(49.0 \%)\end{array}$

0.294 
Table 4: Language of health service provision by Malinké preferred speaker

\begin{tabular}{|c|c|c|c|c|}
\hline & Malinké Speaker (N=99) & Malinké non-speaker (N=59) & Total $(\mathrm{N}=158)$ & $\mathrm{p}$ value \\
\hline Care has been conducted in Malinké & & & & $<0.001$ \\
\hline No & $47(48.0 \%)$ & $58(100.0 \%)$ & $105(67.3 \%)$ & \\
\hline Yes & $51(52.0 \%)$ & $0(0.0 \%)$ & $51(32.7 \%)$ & \\
\hline Care has been conducted in Wolof & & & & 0.006 \\
\hline No & $54(55.1 \%)$ & $45(77.6 \%)$ & $99(63.5 \%)$ & \\
\hline Yes & $44(44.9 \%)$ & $13(22.4 \%)$ & $57(36.5 \%)$ & \\
\hline Care has been conducted in French & & & & $<0.001$ \\
\hline No & $45(45.9 \%)$ & $49(84.5 \%)$ & $94(60.3 \%)$ & \\
\hline Yes & $53(54.1 \%)$ & $9(15.5 \%)$ & $62(39.7 \%)$ & \\
\hline Client received interpretation & & & & 0.724 \\
\hline No & $34(35.8 \%)$ & $18(32.1 \%)$ & $52(34.4 \%)$ & \\
\hline Yes & $61(64.2 \%)$ & $38(67.9 \%)$ & $99(65.6 \%)$ & \\
\hline
\end{tabular}

Table 5: Cervical cancer knowledge by gender 
Aware of cervical cancer

No

Yes

Aware of cervical cancer screening test

No

Yes

Screening is important even without symptoms

Strongly Disagree

Disagree

Undecided

Agree

Strongly Agree

A woman is at increased risk if she has multiple sexual partners

Strongly Disagree

Disagree

Undecided

Agree

Strongly Agree

A woman is at increased risk if her husband has multiple sexual partners

Strongly Disagree

Disagree

Undecided

Agree

Strongly Agree

Smoking increases the risk of cervical cancer

Strongly Disagree

Disagree

Undecided

Agree
1.000

$\begin{array}{lll}32(31.7 \%) & 18(31.6 \%) & 50(31.6 \%) \\ 69(68.3 \%) & 39(68.4 \%) & 108(68.4 \%)\end{array}$

0.619

$\begin{array}{lll}46(46.0 \%) & 29(50.9 \%) & 75(47.8 \%) \\ 54(54.0 \%) & 28(49.1 \%) & 82(52.2 \%)\end{array}$

0.268

$\begin{array}{lll}1(1.0 \%) & 1(1.8 \%) & 2(1.3 \%) \\ 1(1.0 \%) & 2(3.5 \%) & 3(1.9 \%) \\ 2(2.0 \%) & 1(1.8 \%) & 3(1.9 \%) \\ 32(32.7 \%) & 11(19.3 \%) & 43(27.7 \%) \\ 62(63.3 \%) & 42(73.7 \%) & 104(67.1 \%)\end{array}$

0.010

$\begin{array}{lrr}1(1.0 \%) & 3(5.4 \%) & 4(2.6 \%) \\ 6(6.1 \%) & 3(5.4 \%) & 9(5.8 \%) \\ 5(5.1 \%) & 12(21.4 \%) & 17(11.0 \%) \\ 33(33.7 \%) & 16(28.6 \%) & 49(31.8 \%) \\ 53(54.1 \%) & 22(39.3 \%) & 75(48.7 \%)\end{array}$

$<0.001$

$\begin{array}{lll}2(2.0 \%) & 1(1.8 \%) & 3(1.9 \%) \\ 3(3.0 \%) & 1(1.8 \%) & 4(2.6 \%) \\ 4(4.0 \%) & 12(21.4 \%) & 16(10.3 \%) \\ 28(28.3 \%) & 21(37.5 \%) & 49(31.6 \%) \\ 62(62.6 \%) & 21(37.5 \%) & 83(53.5 \%)\end{array}$

0.008

$\begin{array}{ccc}3(3.1 \%) & 3(5.4 \%) & 6(3.9 \%) \\ 18(18.4 \%) & 3(5.4 \%) & 21(13.6 \%) \\ 13(13.3 \%) & 16(28.6 \%) & 29(18.8 \%) \\ 32(32.7 \%) & 24(42.9 \%) & 56(36.4 \%)\end{array}$




\begin{tabular}{|c|c|c|c|c|}
\hline Strongly Agree & $32(32.7 \%)$ & $10(17.9 \%)$ & $42(27.3 \%)$ & \\
\hline IUDs offer a protective benefit against cervical cancer & & & & 0.006 \\
\hline Strongly Disagree & $9(9.1 \%)$ & $3(5.5 \%)$ & $12(7.8 \%)$ & \\
\hline Disagree & $10(10.1 \%)$ & $5(9.1 \%)$ & $15(9.7 \%)$ & \\
\hline Undecided & $30(30.3 \%)$ & $32(58.2 \%)$ & $62(40.3 \%)$ & \\
\hline Agree & $27(27.3 \%)$ & $12(21.8 \%)$ & $39(25.3 \%)$ & \\
\hline Strongly Agree & $23(23.2 \%)$ & $3(5.5 \%)$ & $26(16.9 \%)$ & \\
\hline OCPs increase cervical cancer risk & & & & 0.012 \\
\hline Strongly Disagree & $9(9.2 \%)$ & $4(7.1 \%)$ & $13(8.4 \%)$ & \\
\hline Disagree & $13(13.3 \%)$ & $7(12.5 \%)$ & $20(13.0 \%)$ & \\
\hline Undecided & $24(24.5 \%)$ & $27(48.2 \%)$ & $51(33.1 \%)$ & \\
\hline Agree & $27(27.6 \%)$ & $14(25.0 \%)$ & $41(26.6 \%)$ & \\
\hline Strongly Agree & $25(25.5 \%)$ & $4(7.1 \%)$ & $29(18.8 \%)$ & \\
\hline Screening is recommended after menopause & & & & $<0.001$ \\
\hline Strongly Disagree & $12(12.1 \%)$ & $14(25.5 \%)$ & $26(16.9 \%)$ & \\
\hline Disagree & $44(44.4 \%)$ & $10(18.2 \%)$ & $54(35.1 \%)$ & \\
\hline Undecided & $8(8.1 \%)$ & $18(32.7 \%)$ & $26(16.9 \%)$ & \\
\hline Agree & $9(9.1 \%)$ & $9(16.4 \%)$ & $18(11.7 \%)$ & \\
\hline Strongly Agree & $26(26.3 \%)$ & $4(7.3 \%)$ & $30(19.5 \%)$ & \\
\hline Early screening benefits prevention & & & & 0.816 \\
\hline Strongly Disagree & $1(1.0 \%)$ & $1(1.8 \%)$ & $2(1.3 \%)$ & \\
\hline Disagree & $7(7.1 \%)$ & $2(3.5 \%)$ & $9(5.8 \%)$ & \\
\hline Undecided & $4(4.0 \%)$ & $1(1.8 \%)$ & $5(3.2 \%)$ & \\
\hline Agree & $37(37.4 \%)$ & $22(38.6 \%)$ & $59(37.8 \%)$ & \\
\hline Strongly Agree & $50(50.5 \%)$ & $31(54.4 \%)$ & $81(51.9 \%)$ & \\
\hline
\end{tabular}

Table 6: Experience of cervical cancer screening among those screened in our sample 


\begin{tabular}{|c|c|c|c|c|}
\hline Satisfied with screening & & & & 0.462 \\
\hline Strongly Disagree & $0(0.0 \%)$ & $0(0.0 \%)$ & $0(0.0 \%)$ & \\
\hline Disagree & $1(10.0 \%)$ & $0(0.0 \%)$ & $1(8.3 \%)$ & \\
\hline Undecided & $1(10.0 \%)$ & $0(0.0 \%)$ & $1(8.3 \%)$ & \\
\hline Agree & $0(0.0 \%)$ & $1(50.0 \%)$ & $1(8.3 \%)$ & \\
\hline Strongly Agree & $8(80.0 \%)$ & $1(50.0 \%)$ & $9(75.0 \%)$ & \\
\hline Lengthy wait for screening & & & & 0.099 \\
\hline Strongly Disagree & $1(10.0 \%)$ & $0(0.0 \%)$ & $1(8.3 \%)$ & \\
\hline Disagree & $1(10.0 \%)$ & $1(50.0 \%)$ & $2(16.7 \%)$ & \\
\hline Undecided & $0(0.0 \%)$ & $1(50.0 \%)$ & $1(8.3 \%)$ & \\
\hline Agree & $0(0.0 \%)$ & $0(0.0 \%)$ & $0(0.0 \%)$ & \\
\hline Strongly Agree & $8(80.0 \%)$ & $0(0.0 \%)$ & $8(66.7 \%)$ & \\
\hline Adequate orientation to screening & & & & 0.318 \\
\hline Strongly Disagree & $0(0.0 \%)$ & $0(0.0 \%)$ & $0(0.0 \%)$ & \\
\hline Disagree & $0(0.0 \%)$ & $0(0.0 \%)$ & $0(0.0 \%)$ & \\
\hline Undecided & $0(0.0 \%)$ & $0(0.0 \%)$ & $0(0.0 \%)$ & \\
\hline Agree & $1(10.0 \%)$ & $1(50.0 \%)$ & $2(16.7 \%)$ & \\
\hline Strongly Agree & $9(90.0 \%)$ & $1(50.0 \%)$ & $10(83.3 \%)$ & \\
\hline Screening test was comfortable & & & & 0.136 \\
\hline Strongly Disagree & $2(20.0 \%)$ & $0(0.0 \%)$ & $2(16.7 \%)$ & \\
\hline Disagree & $1(10.0 \%)$ & $0(0.0 \%)$ & $1(8.3 \%)$ & \\
\hline Undecided & $0(0.0 \%)$ & $0(0.0 \%)$ & $0(0.0 \%)$ & \\
\hline Agree & $1(10.0 \%)$ & $2(100.0 \%)$ & $3(25.0 \%)$ & \\
\hline Strongly Agree & $6(60.0 \%)$ & $0(0.0 \%)$ & $6(50.0 \%)$ & \\
\hline
\end{tabular}

\section{Supplementary Files}

This is a list of supplementary files associated with this preprint. Click to download. 
- 18Q04K011234DataComb.csv

- RMarkdownFileCC.pdf

Page 16/16 